\title{
Deposição de calda na cultura da cebola e no solo em função da ponta de pulverização e da pressão de trabalho
}

\section{Spray deposition on onion crops and soil according to spray nozzle and working pressure}

\author{
Dionatan Alan Amler ${ }^{1}$, Fabrício Flávio Amler ${ }^{1}$, Jamille Santos da Silva ${ }^{1}$, Naiara Guerra $^{2}$ e Antonio \\ Mendes de Oliveira Neto ${ }^{3^{*}}$
}

\author{
${ }^{1}$ Instituto Federal Catarinense, Rio do Sul, SC, Brasil. \\ ${ }^{2}$ Universidade Federal de Santa Catarina, Curitibanos, SC, Brasil. \\ ${ }^{3}$ Universidade do Estado de Santa Catarina, Lages, SC, Brasil. Autor para correspondência: antonio.neto@udesc.br
}

Submissão: 12/02/2021 / Aceite: 30/03/2021

\begin{abstract}
RESUMO
A aplicação de agroquímicos vem sendo pesquisada e aprimorada ao longo dos anos, porém ainda há uma carência de pesquisas relacionadas à tecnologia de aplicação na cultura da cebola. Neste trabalho, objetivou-se avaliar a interação de diferentes pontas de pulverização e pressões de trabalho sobre a deposição de calda em plantas de cebola e no solo. O experimento foi constituído de 16 tratamentos e cinco repetições, organizados em esquema fatorial $4 \times 4$, combinando quatro pontas de pulverização (MF 110 015, AD 110 015, TT 110015 e ADIA 110 02) e quatro pressões de trabalho (207, 276, 345 e 414 $\mathrm{kPa}$ ). O trabalho foi conduzido em casa de vegetação com plantas cebolas transplantadas em vasos de $8 \mathrm{dm}^{-3}$ preenchidos com solo. Plantas de cebola com cinco a seis folhas completamente desenvolvidas e placas de Petri acondicionadas no solo foram os alvos biológicos, onde se avaliou a deposição de calda nas plantas e no solo. Utilizou-se o corante azul brilhante como traçador, após a aplicação esse foi recuperado com água destilada e quantificado em espectrofotômetro, para determinação da deposição. A deposição de calda na cebola foi afetada somente pelo fator ponta de pulverização, já no solo foi influenciada pelo modelo de ponta de pulverização, pressão de trabalho e pela interação entre ambos. Concluiu-se que a ponta de impacto (TT 110 015) e a jato plano com indução de ar (ADIA 110 02) foram os modelos que apresentaram maior deposição de calda nas plantas de cebola e no solo. A pressão de trabalho não afetou a deposição de calda nas plantas de cebola. $O$ aumento de pressão incrementou a deposição de calda no solo para as pontas de jato plano (MF 110 015), pré-orifício (AD 110 015) e com indução de ar (ADIA 110 02), contudo não afetou a deposição na ponta de impacto (TT 110 015).
\end{abstract}

PALAVRAS-CHAVE: Allium cepa; taxa de aplicação; deposição foliar de calda.

\begin{abstract}
Pesticide application has been researched and improved over the years, yet there is still a lack of research related to the application technology on onion crops. This work aimed to evaluate the interaction of different spray nozzles and working pressures on the spray deposition on onion plants and the soil. The experiment consisted of sixteen treatments and five replicates, carried out in a $4 \times 4$ factorial scheme, combining four spray nozzles (MF 110 015, AD 110 015, TT 110 015, and ADIA 110 02) and four working pressures $(207 \mathrm{kPa}, 276 \mathrm{kPa}, 345 \mathrm{kPa}$, and $414 \mathrm{kPa})$. The assay was carried out in a greenhouse with onions plants transplanted in pots with a volume of $8 \mathrm{dm}^{-3}$ with soil. Fully developed onion plants with five to six leaves and soil-conditioned Petri dishes were the biological targets for assessing the spray deposition on the plants and the soil. Bright blue coloring was used as a tracer and, after the application, it was recovered with distilled water and quantified using a spectrophotometer to determine the deposition. Spray deposition on the onion plants was affected only by the spray nozzle factor, while deposition on the soil was influenced by the spray nozzle model, working pressure, and the interaction between them. We concluded that the impact (TT 110 015) and air induction (ADIA 110 02) nozzles were the models that presented the highest spray deposition on the onion plants and the soil. The working pressure did not influence the spray deposition on the onion plants. The increase in working pressure raised the spray deposition on the soil for the flat fan (MF 110 015), pre-orifice (AD 110 015), and air induction (ADIA 110 02) nozzles but did not affect the deposition with the impact nozzle (TT 110 015).

KEYWORDS: Allium cepa; application rate; foliar deposition spraying.
\end{abstract}




\section{INTRODUÇÃO}

A cebola (Allium cepa L.) é considerada uma das principais hortaliças em importância econômica para o Brasil (WORDELL FILHO et al. 2006). Entretanto, ela apresenta arquitetura com folhas eretas, cilíndricas, baixo porte e lento desenvolvimento inicial, baixa capacidade de sombrear o solo e reduzida habilidade competitiva, permitindo a germinação e estabelecimento da comunidade infestante durante boa parte do desenvolvimento da cultura, resultando em alto grau de interferência das plantas daninhas (SOARES et al. 2003). Além da redução na produção de bulbos, as plantas daninhas podem influenciar negativamente a qualidade e a classificação comercial dos bulbos de cebola (DURIGAN et al. 2005).

O sucesso na aplicação de pesticidas está diretamente relacionado aos fatores: seleção de pontas, ajuste da taxa de aplicação, parâmetros operacionais, condições ambientais e momento de aplicação. Nesse sentido, variações relacionadas ao volume de aplicação e tamanho das gotas geradas tem relação direta com a quantidade, penetração e distribuição dos depósitos no alvo biológico (FARINHA et al. 2009). Na região do Alto Vale do Itajaí, no estado de Santa Catarina, SC, os produtores de cebolas definem o modelo de ponta de pulverização com pouco critério técnico. Esse cenário é agravado pela carência de pesquisa com tecnologia de aplicação de agroquímicos na cultura da cebola no Brasil.

As pontas de pulverização são os componentes mais importantes de um pulverizador, sendo responsáveis pela determinação da vazão, pela uniformidade de distribuição sobre o alvo biológico e pela formação da população de gotas, que devem apresentar diâmetro compatível com a finalidade da aplicação (GANDOLFO et al. 2013). A utilização de pontas de jato plano com faixa de pressão ampliada permite a formação de uma população de gotas com características distintas, uma vez que com pressão de trabalho entre 100 e $130 \mathrm{kPa}$ produzem gotas mais grossas, que são resistentes à deriva e adequadas à aplicação de herbicidas sistêmicos. Já a operação em pressões próximas a $400 \mathrm{kPa}$, geram gotas mais finas, proporcionando cobertura do alvo compatível com as exigências de herbicidas de contato, inseticidas e fungicidas (BOLLER \& MACHRY 2007).

Neste sentido, em pesquisa conduzida por COSTA et al. (2012) avaliou-se o efeito de pontas e pressão de trabalho sobre a deriva de herbicidas e foi demonstrado que a ponta com indução de ar, modelo Al 110 02, apresentou o menor potencial de deriva. Além disso, os autores ressaltaram que a escolha do modelo de ponta de pulverização e a redução na pressão de trabalho são estratégias eficientes para reduzir deriva na aplicação de agroquímicos. CUNHA \& SILVA (2010) relataram que o aumento na pressão de trabalho em pontas de impacto da série TT e TTJ resultaram em redução no pico central e alargamento do perfil da aplicação, melhorando assim a uniformidade de distribuição volumétrica. VIANA et al. (2008) avaliaram a deposição de calda na cultura da soja com a aplicação com quatro pontas de pulverização (XR 110 02, TT 110 02, TXA 8002 e TJ60 80 02) operando em três pressões de trabalho (276, 552 e $827 \mathrm{kPa})$, os autores concluíram que independentemente da ponta de pulverização a pressão de $276 \mathrm{kPa}$ foi a mais indicada, já que a pressão de trabalho pouco influenciou na deposição de calda.

A partir do exposto, formulou-se a hipótese de que a pressão de trabalho afeta a deposição proporcionada por diferentes pontas de pulverização tipo jato plano, na cultura da cebola. Dessa forma, seria possível estabelecer condições operacionais que garantissem a deposição de calda na cebola sem, contudo, aumentar a deposição em locais fora do alvo, como o solo.

Portanto, esse estudo teve como objetivo avaliar a influência da ponta de pulverização de jato plano e da pressão de trabalho sobre a deposição da calda em plantas de cebola e no solo.

\section{MATERIAL E MÉTODOS}

O experimento foi conduzido em casa de vegetação localizada no município de Rio do Sul (27¹1'20,3" de latitude Sul e 49³9'21,1" de longitude Oeste). O período de condução do experimento foi durante os meses de setembro a novembro de 2018.

O delineamento experimental utilizado foi o inteiramente ao acaso (DIC), com tratamentos organizados em esquema fatorial $4 \times 4$, com cinco repetições. Os tratamentos foram compostos pelo arranjo de quatro pontas de pulverização (jato simples modelo MF 110 015, jato simples com pré-orifício modelo $A D$ 110 015, jato simples de impacto modelo TT 110015 e jato simples com indução de ar modelo ADIA 110 02) operando em quatro pressões de trabalho (207, 276, 345 e $414 \mathrm{kPa})$. Este arranjo resultou em 16 tratamentos, que estão detalhados na Tabela 1.

As unidades experimentais foram vasos plásticos com capacidade volumétrica de $8 \mathrm{dm}^{-3} \mathrm{e}$ preenchidas com solo oriundo de área agrícola. O solo foi previamente peneirado, para a retirada de torrões e resíduos grosseiros. A correção do solo e a adubação foi realizada seguindo as recomendações técnicas para a produção de cebola no estado de Santa Catarina (SBCS 2016). 
Tabela 1. Descrição do modelo de ponta, pressão de trabalho $(\mathrm{kPa})$, vazão individual da ponta $\left(\mathrm{L} \min ^{-1}\right)$ e taxa de aplicação ( $\left.\mathrm{L} \mathrm{ha}^{-1}\right)$ avaliados no experimento. Rio do Sul, SC, 2018.

Table 1. Description of nozzle model, pressure $(\mathrm{kPa})$, individual nozzle flow $\left(\mathrm{L} \mathrm{min}^{-1}\right)$ and application rate $\left(L h^{-1}\right)$ assessed in the experiment. Rio do Sul, SC, 2018.

\begin{tabular}{ccccc}
\hline Tratamento & Ponta & Pressão & Vazão & Taxa \\
\hline T1 & Jato simples - MF 110 015 & 207 & 0,498 & 166 \\
T2 & Jato simples - MF 110 015 & 276 & 0,585 & 195 \\
T3 & Jato simples - MF 110 015 & 345 & 0,653 & 217 \\
T4 & Jato simples - MF 110 015 & 414 & 0,714 & 238 \\
T5 & Pré-orifício - AD 110 015 & 207 & 0,488 & 162 \\
T6 & Pré-orifício - AD 110 015 & 276 & 0,550 & 183 \\
T7 & Pré-orifício - AD 110 015 & 345 & 0,613 & 204 \\
T8 & Pré-orifício - AD 110 015 & 414 & 0,673 & 224 \\
T9 & Impacto - TT 110 015 & 207 & 0,500 & 167 \\
T10 & Impacto - TT 110 015 & 276 & 0,590 & 197 \\
T11 & Impacto - TT 110 015 & 345 & 0,650 & 217 \\
T12 & Impacto - TT 110 015 & 414 & 0,720 & 240 \\
T13 & Indução de Ar - ADIA 110 02 & 207 & 0,655 & 218 \\
T14 & Indução de Ar - ADIA 110 02 & 276 & 0,774 & 258 \\
T15 & Indução de Ar - ADIA 110 02 & 345 & 0,862 & 287 \\
T16 & Indução de Ar - ADIA 110 02 & 414 & 0,930 & 310 \\
\hline
\end{tabular}

Foram transplantadas quatro mudas da cultivar Bola Precoce em cada unidade experimental, essa densidade de plantas foi mantida até a aplicação dos tratamentos. No momento do transplante as mudas estavam com duas folhas completamente expandidas. Durante o período experimental, as plantas foram mantidas em ambiente de casa de vegetação, com fornecimento diário de água, por meio de irrigação localizada. As unidades experimentais foram mantidas livres da presença de plantas daninhas por meio da realização de monda semanal e as doenças foram manejadas por meio da aplicação preventiva de fungicidas.

A aplicação dos tratamentos foi realizada quando as plantas apresentavam de cinco a seis folhas completamente expandidas. Os tratamentos foram aplicados com um pulverizador costal pressurizado a $\mathrm{CO}_{2}$, munido de barra contendo três bicos. A pressão de trabalho e a ponta de pulverização foi ajustada conforme o tratamento (Tabela 1). A altura da barra foi de $0,5 \mathrm{~m}$ em relação ao alvo e a velocidade de deslocamento foi constante de $1,0 \mathrm{~m} \mathrm{~s}^{-1}$.

Antes da aplicação foi coletada a vazão individual de cada ponta para a determinação da taxa de aplicação, em $\mathrm{L} \mathrm{ha}^{-1}$, utilizando o sistema gravimétrico (ANTUNIASSI et al. 2011). As condições do tempo na aplicação foram monitoradas com um termo-higro-anemômetro digital, sendo temperatura do ar de $28,7{ }^{\circ} \mathrm{C}$, umidade relativa de $64 \%$ e velocidade do vento oscilando de 0,5 a $2,7 \mathrm{~km} \mathrm{~h}^{-1}$. Os tratamentos foram aplicados no dia 13/11/2018, com início 16 h00 e término às 16h30min.

A calda aplicada foi composta por água destilada e pelo traçador (Corante Azul Brilhante, FD\&C 1, Duas Rodas, Jaraguá do Sul, SC) utilizado na determinação da deposição. A concentração do traçador foi de $1.000 \mathrm{mg} \mathrm{L}^{-1}$, seguindo a metodologia apresentada por ALVES et al. (2014).

Antes da aplicação foram posicionadas placas de Petri junto ao solo, para interceptação da calda e determinação da deposição no solo. Após a aplicação dos tratamentos, as plantas de cebola e as placas de Petri foram coletadas para a recuperação do traçador e determinação da deposição. A recuperação do traçador se deu por meio de lavagem com volume de $100 \mathrm{~mL}$ de água destilada.

A quantificação do traçador foi realizada por meio de espectrofotômetro, utilizando o comprimento de onda de $630 \mathrm{~nm}$, faixa de detecção do azul, de acordo com a metodologia descrita por PALLADINI et al. (2005). A cultura da cebola foi seca em estufa de circulação forçada de ar a $65^{\circ} \mathrm{C}$, até a obtenção de massa constante. A área de deposição no solo foi determinada a partir do diâmetro da placa de Petri. Os valores de deposição foram convertidos em $\mu \mathrm{L}$ de traçador por $\mathrm{g}^{-1}$ de massa seca e $\mu \mathrm{L}$ de traçador por $\mathrm{cm}^{-2}$, para a 
deposição na cebola e no solo, respectivamente.

Os dados obtidos foram testados quanto a normalidade e homocedasticidade e posteriormente submetidos a análise de variância pelo teste F. Quando significativo, a interação entre modelo de ponta e pressão de trabalho foi desdobrada, sendo o fator modelo de ponta comparado por teste de Tukey e o fator pressão de trabalho submetido a análise de regressão polinomial. Todas as análises foram realizadas adotando-se o nível de significância de $5 \%(p<0,05)$.

\section{RESULTADOS E DISCUSSÃO}

O fator pressão de trabalho e a interação entre ponta de pulverização e pressão de trabalho não influenciaram a deposição de calda sobre a cebola. Apenas o fator ponta de pulverização apresentou significância quanto a deposição na cebola (Tabela 2).

Para a deposição de calda no solo, houve efeito significativo para os fatores ponta de pulverização, pressão de trabalho e para interação entre a ponta de pulverização e a pressão de trabalho (Tabela 2).

Tabela 2. Resumo da análise de variância com para as variáveis deposição na cultura da cebola e no solo. Rio do Sul, SC, 2018.

Table 2. Variance analysis summary for the variables onion crop and soil spray deposition. Rio do Sul, SC, 2018.

\begin{tabular}{lll}
\hline \multirow{2}{*}{ Fonte de variação } & Deposição cebola & Deposição solo \\
\cline { 2 - 3 } & Valor de $p$ & Valor de $p$ \\
\hline Ponta de pulverização (PP) & $<0,01^{*}$ & $<0,01^{*}$ \\
Pressão de trabalho (PT) & $0,53^{\text {ns }}$ & $<0,01^{*}$ \\
PP x PT & $0,35^{\text {ns }}$ & $0,03^{*}$ \\
\hline CV $(\%)$ & 30,06 & 15,18 \\
\hline
\end{tabular}

$\overline{n s}=$ não significativo $(p>0,05) \mathrm{e}=$ significativo $(p<0,05)$.

Houve diferença significativa entre os modelos de ponta de pulverização quanto à deposição na cebola (Tabela 3). Verificou-se que as maiores deposições de calda na parte aérea da cebola, ocorreram principalmente coma ponta de impacto e com indução de ar. Esses resultados divergem com a pesquisa desenvolvida por BAUER et al. (2006), que observaram que a indução de ar reduziu a deposição de calda em mesa de teste para a ponta de jato plano do modelo 11002.

Tabela 3. Deposição da calda $\left(\mu \mathrm{L} \mathrm{g}^{-1}\right)$ nas plantas de cebola em função da ponta de pulverização e da pressão de trabalho. Rio do Sul, SC, 2018.

Table 3. Spray deposition $\left(\mu \mathrm{L} \mathrm{g}^{-1}\right)$ in the onion plants in function of nozzle and pressure. Rio do Sul, SC, 2018.

\begin{tabular}{lc}
\hline Ponta de pulverização & Deposição na parte aérea da cebola $\left(\mu \mathrm{L}{ }^{-1}\right)$ \\
\hline Jato simples & $708,2 \mathrm{~b}$ \\
Jato simples com pré-orifício & $808,1 \mathrm{~b}$ \\
Jato simples de impacto & $1087,7 \mathrm{a}$ \\
Jato simples com indução de ar & $1092,6 \mathrm{a}$ \\
\hline Pressão de trabalho $(\mathrm{kPa})$ & Deposição na parte aérea da cebola $\left(\mu \mathrm{L} \mathrm{g}{ }^{-1}\right)$ \\
\hline 207 & $859,1^{\text {1s }}$ \\
276 & 920,1 \\
345 & 929,7 \\
414 & 987,8 \\
\hline
\end{tabular}

Médias seguidas de mesma letra não diferem entre si pelo teste de Tukey $(p>0,05)$.

${ }^{n s}=$ parâmetros dos modelos polinomiais de primeiro e segundo grau não significativo $(p>0,05)$.

As pontas de impacto e com indução de ar apresentaram a maior deposição na cebola mesmo gerando um espectro de gotas médias a grossas e grossas a extremamente grossas, respectivamente. Estes resultados não eram esperados, pois existe uma relação inversa entre o tamanho de gotas e a cobertura da aplicação (BAESSO et al. 2014). Entretanto, é importante considerar que os diâmetros das gotas geradas apresentam baixo potencial de perda por deriva, o que pode ter contribuído com a maior deposição. 
Os resultados obtidos na pesquisa discordam com os resultados apresentados por CUNHA \& PERES (2010), que avaliaram três pontas: jato plano de impacto, jato plano duplo e jato plano duplo com indução de ar, a ponta com indução de ar promoveu menor cobertura do alvo em virtude de que gotas grossas tem dificuldade de penetrarem no dossel das plantas e da grande desuniformidade da deposição. Além disso, BUENO et al. (2014) constataram que pontas de jato plano com indução de ar produzem espectro de gotas com maior desuniformidade.

Todavia, resultados semelhantes foram obtidos por SILVA et al. (2014), estudando a deposição da calda de pulverização com diferentes modelos de pontas de jato plano em diferentes partes da planta de milho. Tais autores relataram que a ponta de jato plano com indução de ar proporcionou maior deposição de calda em relação a ponta de jato plano na cultura do milho.

Não houve melhoria na deposição de calda na cebola com aumento da pressão de trabalho. $O$ incremento da pressão de trabalho resulta em maior taxa de aplicação (Tabela 1), ou seja, esperava-se maior deposição de calda com o aumento na pressão. Contudo, sabe-se que a cebola é uma planta que naturalmente dificulta a deposição de calda na parte aérea, pela sua arquitetura com folhas eretas, cilíndricas e de baixo porte. As folhas geralmente são cobertas com uma camada cerosa que não possui pilosidade, tendo a superfície lisa que dificulta a deposição de calda (OLIVEIRA NETO et al. 2018). Nesse caso, mesmo com o aumento da pressão de trabalho ou da taxa de aplicação não se observou maior deposição de calda na parte aérea

Os resultados apresentados na pesquisa não corroboram com os obtidos por AZEVEDO et al. (2017), que estudando a interferência do volume de aplicação e adjuvantes nos depósitos da pulverização em plantas de feijão, verificaram que os volumes de aplicação de 160 e $210 \mathrm{~L} \mathrm{ha}^{-1}$ foram os que obtiveram as maiores deposições, diferenciando significativamente dos volumes de 60 e $110 \mathrm{~L} \mathrm{ha}^{-1}$. O volume de aplicação de $210 \mathrm{~L}$ ha ${ }^{-1}$, não aumentou a deposição provavelmente devido a planta ter atingido a capacidade máxima de retenção e consequentemente ocasionando o escorrimento do excesso da calda.

CUNHA et al. (2016) estudando a deposição da calda na cultura da soja, em função de diferentes pressões de trabalho e pontas de pulverização; constataram que o aumento da pressão de trabalho resultou na diminuição da deposição de calda nas folhas inferiores, já nas folhas superiores a pressão de trabalho não contribuiu com a deposição. Entretanto, VIANA et al. (2008), estudando a cobertura de gotas no dossel de soja por diferentes pontas e pressões, relataram que em alguns casos ocorreu aumento e em outro decréscimo na deposição, dependendo da combinação ponta de pulverização e pressão de trabalho.

As pontas de impacto e com indução de ar proporcionaram a maior deposição de calda no solo, independentemente da pressão de trabalho (Tabela 4). Em suma, independentemente do alvo avaliado houve maior deposição de calda com as pontas de jato plano de impacto ou com indução de ar.

Tabela 4. Deposição da calda $\left(\mu \mathrm{L} \mathrm{cm}^{-2}\right)$ no solo em função da ponta de pulverização e da pressão de trabalho. Rio do Sul, SC, 2018.

Table 4. Spray deposition $\left(\mu \mathrm{L} \mathrm{cm}^{-2}\right)$ in the soil in function of nozzle and pressure. Rio do Sul, SC, 2018.

\begin{tabular}{lllll}
\hline \multirow{2}{*}{ Ponta de pulverização } & \multicolumn{4}{c}{ Pressão de trabalho $(\mathrm{kPa})$} \\
\cline { 2 - 5 } & 207 & 276 & 345 & 414 \\
\hline Jato simples & $1,73 \mathrm{~b}$ & $1,51 \mathrm{~b}$ & $1,64 \mathrm{c}$ & $2,20 \mathrm{~b}$ \\
Jato simples com pré-orifício & $1,46 \mathrm{~b}$ & $1,64 \mathrm{~b}$ & $2,07 \mathrm{bc}$ & $1,97 \mathrm{~b}$ \\
Jato simples de impacto & $2,34 \mathrm{a}$ & $2,30 \mathrm{a}$ & $2,84 \mathrm{a}$ & $2,42 \mathrm{ab}$ \\
Jato simples com indução de ar & $2,63 \mathrm{a}$ & $2,45 \mathrm{a}$ & $2,45 \mathrm{ab}$ & $2,93 \mathrm{a}$ \\
\hline
\end{tabular}

Médias seguidas de mesma letra não diferem entre si pelo teste de Tukey $(p>0,05)$.

O aumento da pressão de trabalho contribuiu para aumentar a deposição de calda no solo. Em virtude de o solo ser uma superfície plana e de fácil interceptação das gotas, possivelmente o aumento da taxa de aplicação resultante do aumento de pressão proporcionou a maior deposição no solo.

A pressão de trabalho influenciou de maneira linear positiva a deposição de calda para os modelos de pontas de jato plano simples (Figura 1A) e jato plano com pré-orifício (Figura 1B), ou seja, quanto maior a pressão de trabalho maior a deposição de calda no solo. Em parte, esse comportamento pode ser atribuído ao fato do aumento na pressão de trabalho aumentar a fragmentação da calda, reduzindo assim o tamanho das gotas e aumentando a cobertura (BOLLER \& MACHRY 2007).

Para o modelo de ponta de impacto (Figura 1C), observou-se que o aumento da pressão de trabalho não afetou a deposição da calda no solo. As pontas de impacto, do modelo TT (Turbo Teejet), são indicadas 
para operação em uma ampla faixa de pressão, variando de 100 a $600 \mathrm{kPa}$, no trabalho a pressão avaliada foi de 207 a $414 \mathrm{kPa}$, que segundo o fabricante resulta em gotas de tamanho médio. FREITAS et al. (2005) relataram que a vazão da ponta TT 11002 cresceu com o aumento da pressão, entretanto a deposição na mesa de teste foi semelhante para as pressões de 200, 300 e $400 \mathrm{kPa}$. Esses resultados corroboram com a deposição de calda observada na cebola e no solo.

Para a ponta de jato plano com indução de ar (Figura 1D), observou-se resposta quadrática da deposição com o aumento da pressão de trabalho, sendo que a menor deposição de calda no solo foi obtida com a pressão de $256 \mathrm{kPa}$. Esse comportamento pode ter ocorrido em função do princípio de funcionamento dessa ponta que utiliza o princípio de Venturi para induzir ar ao líquido, gerando gotas de maior diâmetro e com ar em seu interior. Para esse modelo de ponta, ocorre uma correlação positiva entre a pressão de trabalho e a quantidade de ar que é induzido junto a gota, o que modifica o espectro de gotas (FAGGION \& ANTUNIASSI 2010).
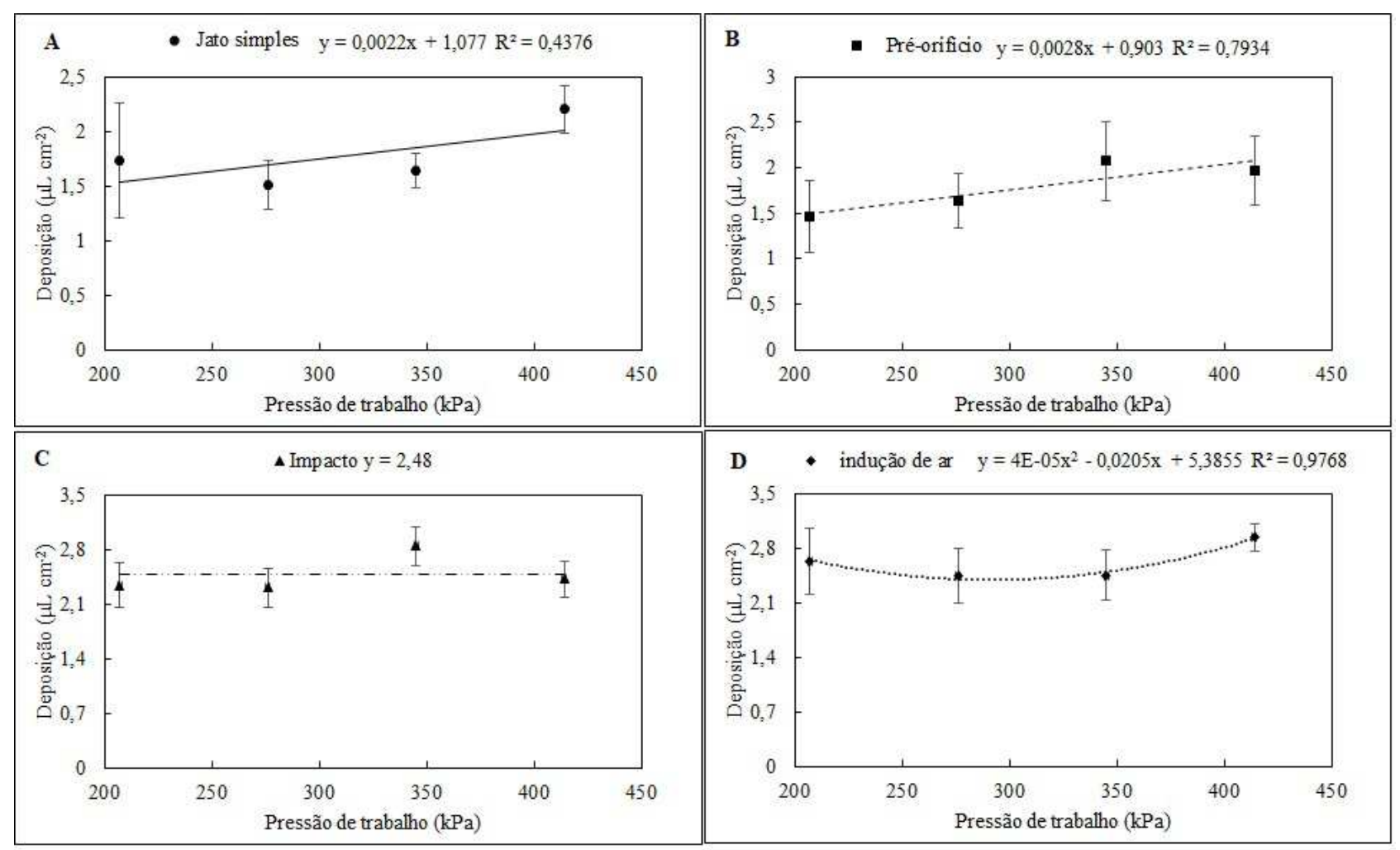

Figura 1. Deposição da calda no solo em função da pressão de trabalho para as pontas jato simples (A), jato simples com pré-orifício (B), impacto (C) e jato simples com indução de ar (D). Rio do Sul, SC, 2018.

Figure 1. Spray deposition in the soil in function of pressure for nozzle fat flan (A), fat flan with pre-orifice (B), impact (C) and fat flan with air induction. Rio do Sul, SC, 2018.

Em síntese, as melhores combinações ocorreram com a ponta de impacto operando a $207 \mathrm{kPa}$ ou com a ponta jato plano com indução de ar operando na pressão de $256 \mathrm{kPa}$. Pois para estes modelos, essas condições operacionais resultaram em maior deposição de calda na cebola e menor deposição no solo. Destaca-se que os resultados experimentais foram obtidos com a aplicação de água e traçador e que a adição de agroquímicos altera as propriedades físico-químicas da calda, podendo alterar o resultado final. Mesmo assim os resultados obtidos são importantes para orientar os profissionais de assistência técnica na definição da ponta de pulverização e da pressão de trabalho a ser adotada na aplicação de agroquímicos na cultura da cebola. Projetos futuros devem ser realizados para validar, em condição de campo, os resultados obtidos em casa de vegetação.

\section{CONCLUSÃO}

A ponta de impacto e jato plano com indução de ar foram os modelos que apresentaram maior deposição de calda nas plantas de cebola e no solo. A pressão de trabalho não afetou a deposição de calda nas plantas de cebola. $O$ aumento de pressão aumentou a deposição de calda no solo para as pontas de jato plano, pré-orifício e indução de ar, contudo não afetou a deposição na ponta de impacto. 


\section{AGRADECIMENTOS}

Ao Instituto Federal Catarinense Campus Rio do Sul pelo Programa Institucional de Bolsas de Iniciação Científica (PIBIC) pela bolsa concedida ao primeiro autor.

\section{REFERÊNCIAS}

ALVES GS et al. 2014. Seleção de traçadores para estudo de eficiência das aplicações de produtos fitossanitários. Planta Daninha 32: 861-870.

ANTUNIASSI UR et al. 2011. Inspeção de pulverizadores de barras. In: ANTUNIASSI UR \& BOLLER W. Tecnologia de Aplicação para culturas anuais. Passo Fundo: Aldeia Norte. p.83-104.

AZEVEDO MG et al. 2017. Interferência do volume de aplicação e adjuvantes nos depósitos da pulverização em plantas de feijão. Revista científica ANAP Brasil 10: 32-43.

BAESSO MM et al. 2014. Tecnologia de aplicação de agrotóxicos. Revista Ceres 61: 780-785.

BAUER FC et al. 2006. Padrões de distribuição volumétrica de pontas de pulverização de jato plano 11002, com e sem indução de ar, sob diferentes espaçamentos e alturas. Engenharia Agrícola 26: 546-551.

BOLLER W \& MACHRY M. 2007. Efeito da pressão de trabalho e de modelos de pontas de pulverização sobre a eficiência de herbicida de contato em soja. Engenharia Agrícola 27: 722-727.

BUENO MR et al. 2014. Deposição de calda e controle de plantas daninhas empregando pulverizador de barra convencional e com barra auxiliar, em volumes de calda reduzidos. Planta Daninha 32: 447-454.

COSTA AGF et al. 2012. Efeito de pontas e pressões de pulverizações na deriva de glyphosate + 2,4-D em condições de campo. Revista Brasileira de Herbicidas 11: 62-70.

CUNHA JPAR \& PERES TCM. 2010. Influência de pontas de pulverização e adjuvante no controle químico da ferrugem asiática da soja. Acta Scientiarum Agronony 32: 597-602.

CUNHA JPAR \& SILVA RAM. 2010. Uniformidade de distribuição volumétrica de pontas de pulverização em função da pressão de trabalho e altura da barra. Bioscience Journal 26: 52-58.

CUNHA JPAR et al. 2016. Deposição da calda da cultura da soja em função de diferentes pressões de trabalho e ponta de pulverização. Revista Ceres 63: 761-768.

DURIGAN JC et al. 2005. Eficácia e seletividade do herbicida flumioxazin aplicado em pré-emergência na cultura transplanta da cebola. Revista Brasileira de Herbicidas 4: 11-17.

FAGGION F \& ANTUNIASSI UR. 2010. Desempenho de pontas de pulverização quanto a indução de ar nas gotas. Energia na Agricultura 25: 72-82.

FARINHA JV et al. 2009. Deposição da calda de pulverização em cultivares de soja no estádio R1. Ciência Rural 39: 1738-1744.

FREITAS FCL et al. 2005. Distribuição volumétrica de pontas de pulverização Turbo Teejet 11002 em diferentes condições operacionais. Planta Daninha 23: 161-167.

GANDOLFO MA et al. 2013. Influência de pontas de pulverização e adjuvantes na deriva em caldas com glyphosate. Ciência Agronômica 44: 474-480.

OLIVEIRA NETO AM et al. 2018. Eficiência e deposição de herbicidas na cebola em função do adjuvante e da taxa de aplicação. Revista Brasileira de Herbicidas 17: e604.

PALLADINI LA et al. 2005. Choice of tracers for the evaluation of spray deposits. Scientia Agricola 62: 440-445.

SOARES DJ et al. 2003. Período de interferência das plantas daninhas na cultura de cebola (Allium cepa) transplantada. Planta Daninha 21: 387-396.

SILVA BM et al. 2014. Deposição da calda de pulverização aplicada com pontas de jato plano em diferentes partes da planta de soja (Glycine max) e milho (Zea mays). Engenharia na Agricultura 22: 17-24.

SBCS. 2016. Sociedade Brasileira de Ciência do Solo. Manual de calagem e adubação para os Estados do Rio Grande do Sul e Santa Catarina. Santa Maria: Palloti. 376p.

VIANA RG et al. 2008. Deposição de gotas no dossel da soja por diferentes pontas de pulverização hidráulica e pressões de trabalho. Engenharia na Agricultura 16: 428-435.

WORDELL FILHO JA et al. 2006. Manejo fitossanitário na cultura da cebola. Epagri: Florianópolis. 266p. 